\title{
DE NUEVo SOBRE LA NATURALEZA DE LA RESPONSABILIDAD de la Administración del Estado
}

\section{Christian Rojas Calderón*}

A propósito de la sentencia que aparece reproducida de manera precedente, se reitera y renueva la discusión en torno a los fundamentos de la responsabilidad del Estado, en este caso por acto dañoso e ilícito.

En efecto, aun a pesar de lo escueto del mismo, se trata en él de cuestiones largamente debatidas por nuestra doctrina, y que aún mantiene plena vigencia ${ }^{1}$.

\section{LOS HechOS}

La sentencia comentada trata del caso de un juicio de indemnización de perjuicios por los daños provocados por el Servicio de Salud de Talcahuano y de la Municipalidad de Penco, fundándola en el hecho de que ambos organismos de la Administración del Estado habrían incurrido en omisión respecto de las prestaciones de salud que correspondía suministrársele a la actora.

En ella, la C. Suprema rechaza el recurso de casación en el fondo deducido en contra de la sentencia dictada por el Tribunal de Alzada

* Profesor de Derecho Administrativo y de Derecho de Aguas de la Universidad Católica del Norte (CHILE). Correo electrónico: chrojas@ucn.cl

1 Vid. en especial, con directa aplicación al caso de la especie a los dos autores paradigmáticos en la disputa sobre estas cuestiones: Pierry ArraU, P.: "Algunos aspectos de la responsabilidad extracontractual del Estado por falta de servicio", en RDJ sección Derecho, Tomo XCII N ${ }^{\circ} 2,1995$, pp. 17-30, "La responsabilidad extracontractual del Estado por falta de servicio" y "¿Es objetiva la responsabilidad del Estado?", ambas en Revista de Derecho del Consejo de Defensa del Estado Año $1 \mathrm{~N}^{\circ} 1$, julio 2000 y $\mathrm{N}^{\circ} 11$, junio 2004 respectivamente; y Soto KLoss, E.: Derecho Administrativo, dos tomos, Editorial Jurídica de Chile, Santiago, 1996, "Responsabilidad del Estado por daños producidos por sus servicios de salud. Notas para un estado de la cuestión en la jurisprudencia", en Ius Publicum $\mathrm{N}^{\circ}$ 12,2004 , pp. 79-87, y sus muchos comentarios sobre jurisprudencia en la materia en la misma revista.

Concurre a esto, por la especial incidencia en el caso comentado, Vásquez Rogat, A.: Responsabilidad del Estado por sus servicios de salud, LexisNexis, Santiago, 1999, 316 pp.; quien sigue a Soto Kloss. 
que negó lugar a la demanda, que había revocado la de primera que la había acogido parcialmente. Sirvió de fundamento para su rechazo el hecho que no se pudo probar la relación causal entre el daño alegado y la falta de servicio.

\section{Naturaleza de La responsabilidad de la Administración DEL ESTADO}

Constituye base del Estado de Derecho ${ }^{2}$, el principio de responsabilidad del Estado/Fisco por los actos que le son imputables en la medida que se produzca algún daño a los administrados/particulares derivados de la falta de servicio.

Esos son los elementos y no otros -ni menos que aquellos-, a que refiere la sentencia que se comenta, al reconocer como fundamentos normativos de la responsabilidad de la Administración del Estado no solo los artículos $6^{\circ}, 7^{\circ}$ y 38 inciso $2^{\circ}$ de la Constitución Política de la República (CPR), sino también los artículos 4 y 44 (actual artículo 42) de la Ley $N^{\circ} 18.575$, Orgánica Constitucional de Bases Generales de la Administración del Estado (LOCBGAE).

Así, por un lado, reconoce -aunque de modo tácito-, que el artículo 38 inciso $2^{\circ} \mathrm{CPR}$ en realidad consagra el principio indicado; y al mismo tiempo reconoce en él una habilitación general a las personas de acceso a la jurisdicción civil o administrativa en caso de cualquier lesión de derechos derivada de la actividad estatal ${ }^{3}$. Y, por otro, hace operativa la expresión del artículo 42 LOCBGAE, referido a la responsabilidad estatal producto "del daño que causen por falta de servicio".

En efecto, como coloca de manifiesto Sanhueza, a propósito de la vieja oposición entre un responsabilidad de Derecho público y otra de contornos generales, abogando por la tesis de la unidad de responsabilidad patrimonial (o de Derecho de daños), se pregunta "ipor qué distinguir un daño causado por una mala praxis médica en una clínica privada de uno provocado en un hospital público?; la actividad es la misma, y no hay razón para hacer responsable al Estado por reglas diferentes a las que gobernarían la responsabilidad de una clínica priva-

Se sigue en ello a Cea Egaña, J. L.: Derecho Constitucional chileno, Tomo I, Ediciones Universidad Católica de Chile, Santiago, 2002, pp. 238-261.

3 En este sentido puede verse a Vergara Blanco, A.: "Prefacio", en Sanhueza Acosta, R., Responsabilidad patrimonial del Estado Administrador cbileno, LexisNexis, Santiago, 2005, PP. XVII-XXII. Puede verse también con idéntica significación a EL MISMO: "Panorama general del Derecho Administrativo Chileno", en González-Varas Ibáñez, S.: Derecho Administrativo Iberoamericano, INAP-IUT, Granada (España), 2005, pp. 168-170. 
da"4; lo que debe conciliarse necesariamente con las normas de Derecho público que rigen este asunto, como las ya indicadas.

De este modo para que pueda condenarse por causa de responsabilidad, es preciso el cumplimiento de los siguientes requisitos $a$ ) existencia de daño o lesión a un particular; $b$ ) una conducta de la Administración que constituya falta de servicio o culpa, y c) relación de causalidad entre el daño sufrido y la falta de servicio.

Por lo cual, no habría dicotomía entre regímenes diversos, salvo en los énfasis que coloque cada uno de ellos, porque se postula que es esta interpretación la que hace operativa y no contradictoria las disposiciones constitucionales y legales indicadas, conciliando adecuadamente ambos cuerpos normativos 5 .

\section{Elementos estructurales de la Responsabilidad patrimo- NIAL DE LAS ADMINISTRACIONES PÚBLICAS}

Lo antes expuesto permite reconocer, por medio de la concatenación de ambos cuerpos normativos, los ELEMENTOS ESTRUCTURALES de la responsabilidad patrimonial de las administraciones públicas, a saber: lesión de derechos, nexo causal, y funcionamiento de los servicios públicos ${ }^{6}$.

\section{Lesión de derechos}

Aunque es únicamente el artículo 38 inciso $2^{\circ} \mathrm{CPR}$ que habla de lesión de derechos -el resto de las normas indicadas hablan de daño-, se ha preferido por considerarla más expresiva y comprensiva.

En primer lugar cabe señalar que conforme el texto de las disposiciones que sirven para construir el régimen de responsabilidad, solo es necesaria la acreditación de un daño o lesión de derechos, sin que sea exigencia acreditar la existencia de dolo o culpa del ente productor. De este modo estaríamos en presencia de un daño o lesión objetiva, es decir, basta que se produzca por los supuestos que señala la normativa de la especie, sin que sea necesaria la prueba de la conducta antijurídica del infractor.

4 Sanhueza Acosta, R.: Responsabilidad patrimonial del Estado Administrador chileno, LexisNexis, Santiago, 2005, p. 80.

5 Hay además un matiz de política jurídica en ello, conforme lo cual un régimen de responsabilidad objetiva pura, basado en el concepto de daño, causado por la actividad administrativa normal o anormal, lícita o ilícita, es inasumible económicamente por cualquier Estado y en definitiva por todos nosotros.

6 Vid. en este orden a DE Ahumada Ramos, F. J.: La responsabilidad patrimonial de las administraciones públicas, segunda edición, Aranzadi, Elcano (Navarra), 2004, pp. 147-347. 
En segundo lugar, dicho daño debe ser efectivo, es decir, individualizable, actual y real; adicionalmente debe haber afectado dañosamente los bienes o derechos de la persona; y debe ser avaluable económicamente ${ }^{7}$.

De este modo, así delimitado el concepto, los daños a simples intereses legítimos no son de suyo indemnizables, salvo que una ley expresamente lo establezca

\section{Nexo causal}

Como bien señala la sentencia, para que la responsabilidad de la especie pueda ser reclamada deberá existir y acreditarse en juicio, un vínculo de causalidad entre la falta de servicio -producida por vía de acción u omisión-, y el resultado nocivo en términos de que aquella sea determinante en la generación del evento dañoso.

Lo que importa a este respecto, es determinar si mediante un comportamiento activo u omisivo se ha causado por la actividad administrativa el daño o la lesión del derecho que se invoca. Sin embargo, más que una cuestión de orden material, se trata de una cuestión de índole esencialmente jurídica entre un comportamiento y la vulneración de un derecho, esto es, sobre la base concreta de la transgresión del derecho de su titular y el agente o agentes que concurren a su privación.

Es por ello que resulta necesario para que la Administración esté obligada a indemnizar, la acreditación que la actividad/inactividad administrativa haya sido la causa del daño, que constituye lesión de un derecho ${ }^{8}$.

En el caso de marras, precisamente este asunto es el que no se acreditó con la prueba agregada al expediente, por lo cual se desestimó la pretensión de la demandante.

\section{Mal funcionamiento de los servicios públicos}

Como ha dicho la sentencia y reconoce la doctrina, hay mal funcionamiento de los servicios públicos cuando los órganos o agentes estatales no actúan debiendo hacerlo, o cuando su accionar es tardío o defectuoso, provocando en uno u otro caso, un daño a los usuarios del respectivo servicio público. Por ende, constituirá "falta de servicio" -constitutiva del mal funcionamiento de los mismos- cualquier falta a las obligaciones

En estas caracterísiticas se sigue el orden propuesto por SANTAMaría PASTOR, J. A.: Principios de Derecho Administratrivo general, tomo II, Iustel, Madrid, 2004, pp. 492-507.

8 Cuestión harto compleja de acreditar, más aún por la existencia en muchos casos de concurso y concurrencia de causas. 
del servicio particular, las que serían casi imposibles de enumerar por las distintas atribuciones competenciales de cada uno. Por vía ejemplar, la Jurisprudencia ha dicho que la hay: en una acción u omisión; en una actuación voluntaria, en una imprudencia o torpeza; en un defecto de la organización del servicio; en una falla de funcionamiento del servicio; en una ilegalidad; o en una simple operación material ${ }^{9}$.

Ello nos lleva necesariamente a considerar esta noción de la "falta de servicio" como fuente generadora directa de la responsabilidad del Estado, constituyendo el criterio adecuado de imputabilidad, que existirá aunque no quepa identificar culpa o negligencia individualizada alguna, es decir que la falta determinante de la anormalidad puede muy bien ser una falta objetiva.

Al mismo tiempo, dicha noción cumple con la función de ser un criterio adecuado de control de la actividad administrativa, cada vez más intensiva y extensiva en las distintas zonas de relevancia económica en el marco de desarrollo de nuestro país.

\section{REFERENCIAS BIBLIOGRÁFICAS}

- Cea Egaña, José Luis: Derecho Constitucional chileno, Tomo I, Ediciones Universidad Católica de Chile, Santiago, 2002.

- De Ahumada Ramos, Francisco Javier: La responsabilidad patrimonial de las administraciones públicas, segunda edición, Aranzadi, Elcano (Navarra), 2004.

- Pierry Arrau, Pedro: "Algunos aspectos de la responsabilidad extracontractual del Estado por falta de servicio", en RDJ, sección Derecho, Tomo XCII No 2, 1995.

_ _ _ _ _ _ _ _ _ _ _ _ ___ responsabilidad extracontractual del Estado por falta de servicio", en Revista de Derecho del Consejo de Defensa del Estado, Año $1 \mathrm{~N}^{\circ} 1$, julio 2000.

- $\quad$ : “Es objetiva la responsabilidad del Estado?", en Revista de Derecho del Consejo de Defensa del Estado $\mathrm{N}^{\circ} 11$, junio 2004.

- Sanhueza Acosta, Ricardo: Responsabilidad patrimonial del Estado Administrador chileno, LexisNexis, Santiago, 2005.

- Santamaría Pastor, Juan Alfonso: Principios de Derecho Administratrivo general, tomo II, Iustel, Madrid, 2004

- Soto Kloss, Eduardo: Derecho Administrativo, dos tomos, Editorial Jurídica de Chile, Santiago, 1996.

9 Para un desarrollo más completo de esta parte, ver a SANHUEZA, Responsabilidad..., op, cit. pp. 167-175. 
: "Responsabilidad del Estado por daños producidos por sus servicios de salud. Notas para un estado de la cuestión en la jurisprudencia", en Ius Publicum $\mathrm{N}^{\circ}$ 12, 2004.

- VÁsquez Rogat. Andrés.: Responsabilidad del Estado por sus servicios de salud, LexisNexis, Santiago, 1999.

- Vergara Blanco, Alejandro: "Prefacio", en Sanhueza Acosta, R., Responsabilidad patrimonial del Estado Administrador chileno, LexisNexis, Santiago, 2005.

: "Panorama general del Derecho

Administrativo Chileno", en González-Varas Ibáñez, S.: Derecho Administrativo Iberoamericano, INAP-IUT, Granada (España), 2005. 